\title{
Mulheres fora do teatro
}

\section{Bruno Schiappa}

Mulheres em recreio, de autor anónimo.

${ }^{1}$ Este trabalho foi realizado no âmbito do projecto de investigação

"História do Teatro

Português online"

financiado pela FCT (PTDC/HAH/72397/2006), desenvolvido no Centro de Estudos de Teatro da Universidade de Lisboa.

Bruno Schiappa é actor e encenador de

teatro e Mestre em Estudos de Teatro pela Faculdade de Letras da Universidade de Lisboa. Prepara actualmente, com uma bolsa da FCT, um doutoramento na mesma área científica na FLUL.

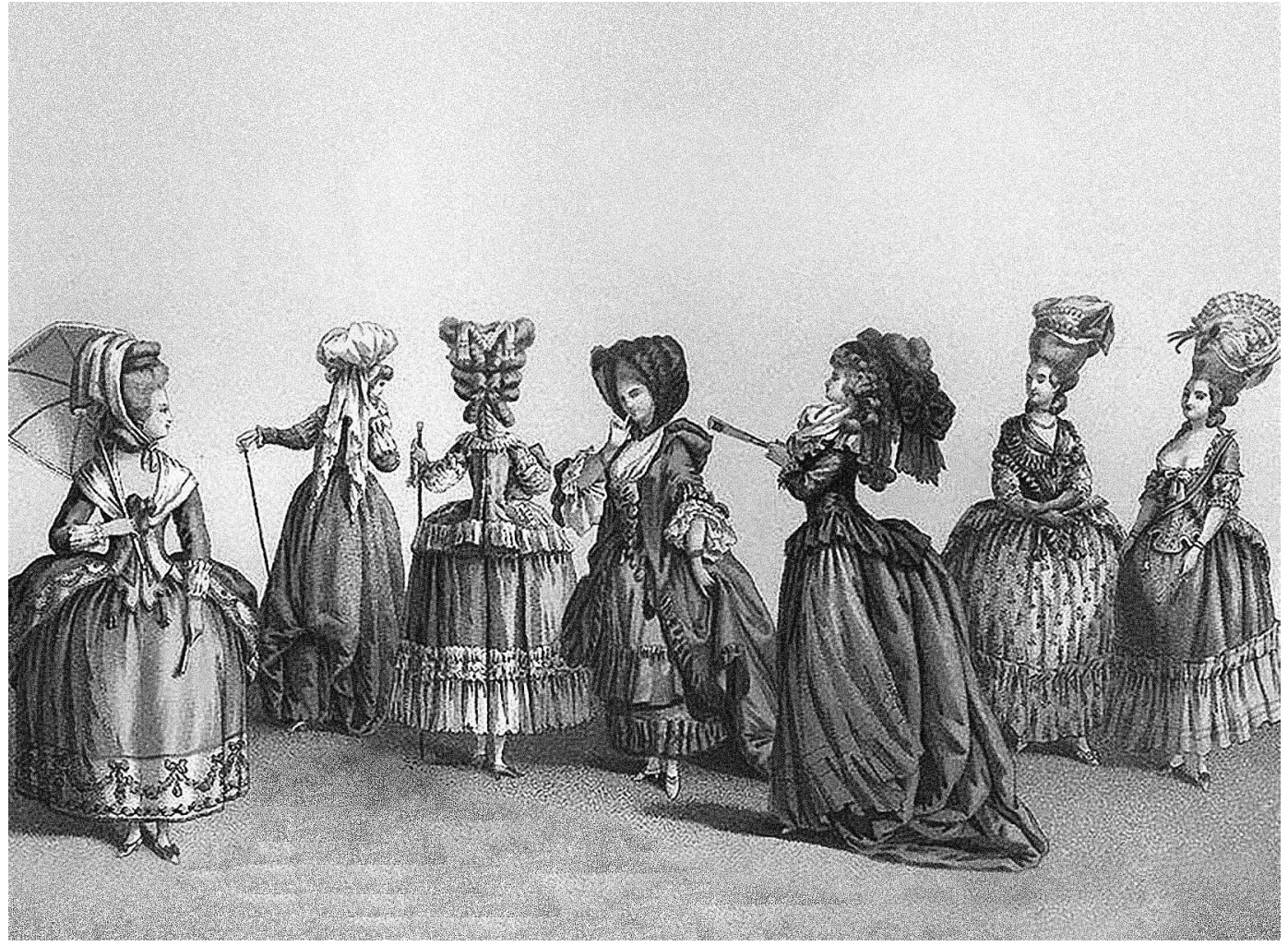

Durante o séc. XVIII, as mulheres estavam proibidas de actuar, primeiro, nos espectáculos de Corte e, mais tarde, nos teatros públicos. Durante o reinado de D. Maria I, chegaram mesmo a ser banidas não apenas dos palcos, mas também do auditório. Esta circunstância limitou a evolução do Teatro em Portugal e tornou mais moroso o desenvolvimento da sociedade portuguesa no que diz respeito às ideias promovidas pelo lluminismo. 0 lluminismo considerava o teatro uma escola de civilização, um moderador de vicios e um construtor de moralidade e, para que tal acontecesse, devia ser sempre vraisemblable. Mas a atmosfera teatral portuguesa - na qual apenas os homens representavam todos os papéis - considerada ridícula por muitos estrangeiros que visitaram Portugal na altura, não podia ser um grande contributo para a concretização desse título tão elevado que o resto do mundo ocidental conferia ao teatro.

As mulheres gradualmente banidas do teatro Já durante os últimos anos do reinado de João V, as mulheres começaram a ser afastadas dos teatros de Corte. Durante o reinado de D. José I, devido ao profundo ciúme da rainha Mariana, não eram sequer admitidas entre o público nos espectáculos reais. Em 1772, dois estrangeiros, Richard Twiss e William Wraxall, escreveram:

A 17 de Novembro, desloquei-me ao palácio do rei, em Belém (...) onde assisti à ópera italiana Ezio. A orquestra é excelente; não se admitem mulheres, excepto as da casa real, a este espectáculo. Também não são admitidas no teatro: castrados disfarçados de mulheres tomam o seu lugar, e a ilusão é perfeita. Mas chocou-me ver os ballets dos intervalos executados por homens, cujas barbas negras e largos ombros sob trajos de mulher não inspiram nada de agradável. Este costume invulgar é atribuido ao ciúme da rainha. (Twiss apudCarreira 1988: 391)

Uma circunstância distinguia estas representações de tudo o que eu tinha visto noutros locais; poderá parecer bastante extraordinário, pelo que dificilmente a acreditarão: as mulheres eram completamente excluídas, não só da sala, mas também do palco; assim, nenhuma podia ser espectadora nem actriz. (Wraxall apudibidem) 
Depois da morte de D. José e a seguir a um hiato teatral de dois anos, as mulheres foram banidas dos Teatros Públicos. Laureano Carreira afirma que, nesta altura, as mulheres apenas actuavam em casas particulares (Ibidem: 398). Com D. Maria I, a aplicação das medidas que proibiam as mulheres nos palcos tornou-se tão forte que "a proibição de subirem mulheres ao palco aparece como condição sine qua non para que um texto teatral possa ser representado" (Eleutério 2003: 278). Tal afirmação significa que, para conseguir licença da Real Mesa Censória para que um texto fosse levado a cena, os empresários teatrais tinham que declarar que o mesmo seria exclusivamente representado por homens. D. Maria I defendia que tal imposição visava a manutenção da moral e bons costumes.

Numa carta de 1779, Arthur William Costigan (pseudónimo literário do Major português Diogo Ferrier) escreveu:

\section{Meu querido irmão:}

Prometi numa das minhas cartas contar-vos uma representação teatral a que assistimos. Foi uma autêntica farsa; na minha maneira de ver, excedeu em ridículo e burlesco tudo quanto de mais grosseiro, mesmo nos tempos mais rudes, foi alguma vez produzido no teatro. Agora não há aqui teatro público, pois a piedosa rainha não permite uma escola pública de imoralidade; menos ainda admitiria que mulheres aparecessem em cena. É de opinião que consentir às mulheres que se exibam desta maneira em público é parecer patrocinar o vício favorito do pais; visto que a principal preocupação é evitar o escândalo. Isto confirma o que já disse em tempos, assim como concorda com o conselho que os velhos frades, neste país, dão sempre aos novos: si non caste tantum modo caute, se não podeis ser casto ao menos sede cauteloso. Em conformidade com estas razões, Sua Majestade, mercê da sua autoridade absoluta, pode proibir às mulheres de representarem em público: elas, porém, agradecem a Deus o não poder ela impedir de representarem em particular. (apud Carreira 1988: 476)

Independentemente de as razões acima aduzidas ou o profundo ciúme da rainha terem sido a causa de tais medidas, o facto é que apenas em 1800 as mulheres foram, oficialmente, autorizadas a regressar aos palcos nacionais.

\section{Testemunhos de estrangeiros sobre o teatro em Portugal}

Vários viajantes deixaram as suas impressões sobre a vida teatral em Portugal durante o séc. XVIII. Seleccionei os testemunhos de três desses estrangeiros que visitaram o nosso país entre 1787 e 1797. William Beckford (17601844) esteve em Portugal em 1787/88 e de novo em 1794:

Estive mais entretido do que esperava, apesar da récita durar mais de quatro horas e meia, das sete até perto da meianoite. Compunha-se o espectáculo de uma empolada tragédia em prosa, em três actos, intitulada Sesostris, dois bailados, uma pastoral, e uma farsa. As decorações não eram más, e os trajos eram pomposos.

Um jovem de andar incerto, e olhar turvo, trajando o mais pesado luto, guinchou e roncou alternadamente o pape de uma princesa viúva. Outro adolescente, mal seguro nos seus sapatos de tacões altos, representava a Sua Majestade egipcia, e garganteou duas árias com toda a nauseabunda suavidade de um aflautado falsete.

Conquanto eu tivesse vontade de thes esmurrar os ouvidos, por me terem tão grosseiramente aturdido os meus, o auditório foi de mui diversa opinião, e aplaudiu-os com o maior entusiasmo. (Beckford 1835: 239-40, tradução nossa)

Duc du Châtelet (1727-1793) esteve em Portugal em ano incerto e os seus escritos foram publicados em 1799:

Para levar ao cúmulo da repugnância que inspiram as suas representações dramáticas, uma falsa ideia de decência afastou completamente as mulheres, e temos de nos resignar a ver representar por homens, que nem sempre são imberbes, os papéis de rainhas, de princesas e de amorosas. 0 belo sexo é excluído mesmo dos ballets. 0 reportório dos seus actores tem sido composto em grande parte, nestes últimos tempos, pelas melhores peças traduzidas do francês, do italiano, num grande número do espanhol e algumas somente do inglês. Traduziram mesmo várias das nossas óperas-cómicas. Mas as suas peças favoritas são ainda as que Ihes contam os mistérios da paixão e outros aspectos do Livro Sagrado; aquelas que representam Jesus Cristo, a Virgem Santa e os Santos. (Châtelet 1799: 83, tradução nossa)

Robert Southey (1774-1843) esteve em Portugal nos anos de 1979 e 1800 e escreveu:

A ópera italiana, cujo absurdo exige uma tal perversidade, é normalmente aguardada aqui com interesse. A rainha actual não admite que as mulheres apareçam no palco, e esta medida, na verdade uma consequência do seu ciúme, dizem que procede da sua preocupação pela moral pública. Tinha sido dada permissão, quando eu cheguei, para que uma bailarina se exibisse e o teatro estava esgotado por essa razão. Onde estava a preocupação da rainha com a moral pública 
quando permitiu tal? Não se deveria autorizar nenhum

D. Maria I (reinou 1777-1816), de autor anónimo. divertimento que não fosse benéfico para o espectador e fosse vicioso para o intérprete. Tais proibições de indole espartana seriam vistas como despóticas nos nossos Estados modernos e liberais, onde leis sumptuárias são consideradas entraves à liberdade. (Southey 1799: 345-46, tradução nossa)

Como se pode inferir, o resultado de homens a representarem mulheres não era, nestes casos, muito agradável. De acordo com estes três testemunhos, podemos imaginar que, para o público local, o resultado fosse igualmente ridículo, grotesco ou, pelo menos, cómico. Seria esse, seguramente, o efeito de uma caricatura constante $\mathrm{e}$, desse modo, não honraria o teatro.

Pina Manique e o afastamento das mulheres do palco e dos auditórios

A 15 de Dezembro de 1780, dando o seu parecer acerca de um pedido de Licença para espectáculos de teatro, Pina Manique escrevia a D. Maria I o seguinte:

Todos este motivos me parecem os Supp. ${ }^{\text {tes }}$ dignos da graça que pretendem muito principalm. ${ }^{\text {te }}$ sendo as representaçoens todas feitas por homens com o q' não pode haver receio aconteçam aquelles desturbios q. são infalíveis quando se dá hum gr. ${ }^{\text {de }}$ ajuntam. ${ }^{\text {to }}$ de Pessoas de ambos os Sexos. E para cortar qualquer abuzo q. se possa introduzir será precizo que debaixo de qualquer pretexto que se alegue se não

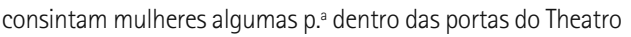
da reprezentação, bastedores e Cazas de Senario e vestuario; e q. nos Camarotes não haja cortinas nem se consintam mulheres e Meretrizes q. vão servir de escolho á virtude. (Intendência Geral da Polícia, Livro I, f. 86v/87)

Luisa Todi foi a actriz/cantora portuguesa mais famosa do séc. XVIII. Trabalhou em Lisboa, seguindo depois para o Porto onde trabalhou entre 1771 e 1776, altura em que deixou Portugal para trabalhar no estrangeiro, tornandose muito famosa e actuando nos mais prestigiados palcos da Europa. Apesar da importância diplomática do facto de fazer chegar o nome de Portugal onde quer que actuasse, sofreu as medidas restritivas que não permitiam às mulheres actuarem nos palcos portugueses. Só lhe foi permitido o regresso para cantar em 1793, por ocasião da celebração do nascimento da Princesa da Beira, Maria Teresa de Bragança. Todi precisou de um visto especial que só Ihe foi concedido devido à intervenção da Imperatriz da Prússia e ao pedido feito pelo diplomata português

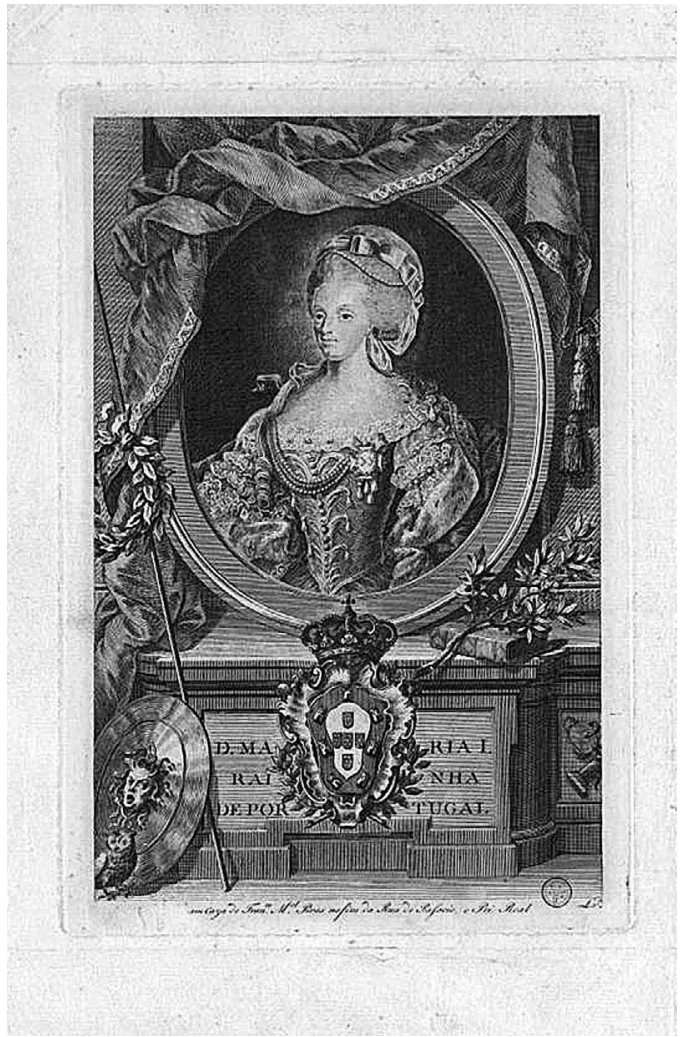

destacado naquela Corte. Foi o próprio Pina Manique quem a aceitou para a celebração, mas Victor Eleutério refere que "A frieza da recepção, a ausência da família real, a falta de entusiasmo por parte do auditório, assinalavam dramaticamente a diferença em presença da actriz cantora mais famosa da Europa" (Eleutério 2003: 263).

Luisa Todi regressaria a Portugal em 1799, acabando por morrer em 1811, pobre e cega. A 21 de Junho de 1793 o mesmo Intendente pedia a D. Maria I permissão para mudar o nome do novo Teatro de Ópera, de Princesa do Brasil, para São Carlos:

Restame agora só rogar a S. A. queira dignar-se permitir a licença de se denominar o Theatro da Princeza do Brazil com o Titulo de S. Carlos, e que o Mesmo Senhor quizesse honrar aquella Caza vindo assistir no dia, que o ditto Senhor assignalar para a sua abertura, o que os seos Vassallos esperão anciozam.te, e receberem esta honra em satisfação do gosto, e disvello, com que a Policia emprehendeo a ditta 
obra para ornamento desta famoza Capital, e o mais que hé prezente a S. A. (Intendência Geral da Polícia, Livro IV, f. 38v)

0 teatro tinha sido construído com fundos providenciados por vários comerciantes e as receitas reunidas eram destinadas ao financiamento do bom funcionamento da Casa Pia, um Orfanato para rapazes fundado por Pina Manique. D. Maria I não estava interessada em promover um Teatro, uma vez que tinha sido decisão sua o afastamento das mulheres dos palcos oficiais, logo, para que um teatro público obtivesse a sua bênção era melhor que tivesse um título religioso. Uma vez que o arquitecto do S. Carlos - José da Costa e Silva - tinha seguido o plano do teatro S. Carlo em Nápoles, a escolha do nome era fácil. De facto, se estas estavam proibidas de actuar como poderia um Teatro ter o nome de uma mulher e, principalmente, de uma mulher da realeza? 0 facto de o Teatro S. Carlos ter sido nomeado, anteriormente, Teatro da Princesa do Brasil, induziu em erro alguns dos nossos historiadores sobre a origem do actual nome.

\section{A extensão do preconceito}

Parafraseando Roland Barthes, as mentalidades demoram mais tempo a mudar do que as ideologias. 0 preconceito pertence ao âmbito da mentalidade e, por isso, quando se instala, mesmo que as circunstâncias sociais e políticas mudem, aquele permanece inalterável por longo tempo. A 3 de Janeiro de 1805, o Intendente da Polícia à época, ainda sob a autoridade de D. Maria I (apesar de a loucura desta estar já num estado muito avançado e de o seu filho ser o regente desde 1799), escreveu nos Livros da Intendência Geral da Polícia:

Reprezentando-me Agostinho Catalani, que em sua propria Caza havia sido insultado por Jozé Antonio Caminha, Lucio Jozé Bolonha, e Manoel Izidro da paz, dando-Ihes algũas bofetadas, e pertendendo lança-lo pela escada abaixo por querer o Sobredito Agostinho Catalani conservar a honra da sua caza, e não os consentir nella; não deferi logo a esta reprezentação por elle ma fazer pelas nove horas da noite do dia Vinte e Oito de Dezembro proximo passado, e por pensar que esta queixa fosse effeito de demaziados licores, que houvesse bebido: na manhãa porém do dia seguinte, Veio banhado em lagrimas repertir-me a mesma reprezentação, expondo-me novamente, que não queria perder a boa opinião, em que sempre tinha conservado sua mulher, e filha tanto na Italia, como em diversos Paizes da
Europa, onde havia estado. Hé certo, que nenhum Pai de familia está obrigado a admitir em sua Caza pessoa algũa contra sua vontade; Hé igualm. ${ }^{e}$ certo, que a mulher, e filhos estão sujeitos áquelle; e que o recorrente tem dado provas de que conserva sua mulher, e filha sem nota alguma no seo preocedimento, o que assas raro entre gentes que se occupão em Theatros. (Intendência Geral da Polícia, Livro VIII, f. 85v)

Tanto a esposa como a filha de Catalani eram actrizes e cantoras e o episódio teve lugar a seguir a uma estreia no Teatro S. Carlos.

Quer devido a uma autoridade déspota ou sob razões de ordem religiosa, a censura contra as mulheres criou um abismo ainda maior do que aquele que já existia entre Portugal e o resto da Europa. Limitou a evolução teatral porque ignorou a importância das mulheres para veicularem emoções femininas. Falhando este aspecto, o papel do teatro enquanto "escola de civilização" também falhava. Em consequência, as ideias do lluminismo não tiveram, entre a população portuguesa, o esperado alcance, pelo menos no que diz respeito ao teatro. Foi um retrocesso em relação ao que o Marquês de Pombal tinha avançado. Foi um retrocesso em relação ao resto do mundo. Foi esta a consequência de uma situação que durou mais de duas décadas. Uma situação que manteve o público afastado da verdade e da seriedade, privando-o de ver mulheres a actuarem. Foram estas as consequências de manter as mulheres fora do teatro, silenciando as vozes das mesmas e proibindo as suas vidas.

\section{Referências bibliográficas}

AA. W., Contas da Secretaria da Intendência Geral da Policia, Livros I, IV e VIII, A. N. T. T.

BECKFORD, William (1835), Italy, with Sketches of Spain and Portugal, Vol. II, London, Richard Bentley.

CARREIRA, Laureano (1988), O Teatro e a censura em Portugal na segunda metade do séc. VXIII, Lisboa, Imprensa Nacional - Casa da Moeda.

CHÂTELET, Duc du (1799), Voyage en Portugal, vol. II, B.

ELEUTÉRIO, Victor Luis (2003) Luisa Todi, Lisboa, Montepio Geral.

SOUTHEY, Robert (1799), Letters Written during a Short Residence in Spain and Portugal, Bristol, Longman and Rees. 